\title{
O lugar do PNBE e do PIBID na e para a formação de leitores
}

\author{
Ana Paula Franco Nobile Brandileone ${ }^{1}$ \\ Vanderléia da Silva Oliveira ${ }^{2}$
}

\section{A formação do professor e a leitura}

Em meio aos constantes debates que perpassam o meio acadêmico sobre leitura e seus desdobramentos, a reflexão sobre a formação do professor leitor não pode ser subtraída. É necessário abrir espaço para o relato sobre a formação leitora e as experiências de letramento dos acadêmicos em formação, futuros professores de literatura e mediadores.

Normalmente, considera-se que o professor está preparado para lecionar quando domina os conteúdos relativos à sua disciplina e tem conhecimentos suficientes de metodologia, ou seja, quando está ciente do que e de como ensinar. Mas, a pergunta é: de que forma ele integrará em suas atividades a prática da leitura? Cabe ao professor leitor vencer o desafio de estabelecer o diálogo dos alunos com o mundo, utilizando todos os tipos de textos com os quais convivem diariamente. Daí decorre a importância do professor em formação obter subsídios teóricos sobre leitura e gêneros textuais que propiciem a ele o aprimoramento de suas relações com os textos, particularmente nos processos de produção e recepção.

Em pesquisa sobre o ensino de literatura nos cursos de licenciatura em letras (Oliveira, 2007), área na qual a leitura é condição primeira para compreensão, interpretação e produção de textos, constatou-se que o professor de literatura acaba por repetir fórmulas prontas adquiridas durante o percurso da educação básica e sacralizadas na graduação. Naquela, seu contato com o texto literário, quando muito, se deu com a literatura infanto-juvenil e, posteriormente, com a historicização literária no ensino médio. No superior, ele volta a se deparar com a

\footnotetext{
${ }^{1}$ Doutora em letras e professora da Universidade Estadual do Norte do Paraná (UENP), Cornélio Procópio, PR, Brasil. E-mail: apnobile@uenp.edu.br.

${ }^{2}$ Doutora em letras e professora da Universidade Estadual do Norte do Paraná (UENP), Cornélio Procópio, PR, Brasil. E-mail: vances@uenp.edu.br.
} 
periodização estilística e a ter uma repetição da "evolução linear" da produção literária brasileira. Assim, sua formação não se dá no campo da análise de obras concretas (de fruição estética), mas, sim, no da memorização de escolas, autores e obras de determinado período. Por isso, sua concepção do ensino de literatura acaba voltada para uma abordagem pragmática e intermediária, como salienta Zilberman (1991), ainda na década de 1980, quando as discussões sobre leitura e ensino de literatura começaram a despontar fortemente no cenário brasileiro.

Vale lembrar que a formação de professores de literatura brasileira, até o início da década de 1930, esteve ligada a uma tradição histórica, assim como a de língua materna esteve ligada à tradição filológica e gramatical. A partir desse período, embora com implantação dos cursos de letras no país, os objetivos previstos para a formação dos profissionais das letras não bastaram para erradicar certos desacordos existentes. O ensino de literatura brasileira nos cursos de graduação ainda traz em si entraves não somente burocráticos mas também aqueles ligados à própria conceituação do que é literatura e o porquê de estudá-la. Além disso, muitos destes entraves, específicos da disciplina, estão ligados à própria criação dos cursos de letras, que traz em si a dicotomia de formar professores para o magistério de um lado e pesquisadores de outro.

É importante dizer, entretanto, que após a promulgação da Lei $n^{\circ}$ 9.394/1996 - Lei de Diretrizes e Bases da Educação Nacional (LDB) -, teve início uma série de discussões sobre a reorganização dos cursos de licenciaturas no país. Por isso mesmo, as normas estabelecidas pela Resolução CNE/CP n ${ }^{\circ}$ 2/2002, decorrente das reformulações propostas pela LDB, sobretudo no que se refere à flexibilização curricular, bem como os pareceres do Conselho Nacional de Educação $(\mathrm{CNE})^{3}$ sobre as diretrizes curriculares para a formação de professores, representaram uma possibilidade de mudança, tendo em vista que exigiu dos cursos de Letras, assim como de outras licenciaturas, a reformulação de seus projetos político-pedagógicos sob uma perspectiva mais integrada entre as várias áreas de formação. Assim, na formação do professor de letras deveria estar contemplada a prática voltada para o encaminhamento metodológico dos conteúdos teóricos das disciplinas. Afinal, pelas referências existentes sobre a história dos cursos de letras no país e seus

\footnotetext{
${ }^{3}$ Ver especialmente os pareceres $n^{\text {os }} 776 / 1997,492 / 2001$ e $1.363 / 2001$.
} 
currículos, sabe-se que a formação pedagógica - mesmo o curso tendo o caráter, desde o início, de formar professores - não era contemplada, sendo que, apenas em $1969^{4}$ foi determinado que os currículos que legitimavam o magistério deveriam ter disciplinas pedagógicas e prática de ensino nas disciplinas de habilitação. No entanto, mesmo com esta obrigatoriedade, sempre houve - e ainda há - uma lacuna entre os professores da área de metodologia e prática de ensino e os das disciplinas específicas. Isto porque, de modo geral, os docentes da área de letras julgam que a formação pedagógica não é tarefa deles, deixando de lado a preocupação com "o que" e "como" ensinar. De acordo com as diretrizes específicas da área constantes do Parecer CNE/CES $\mathrm{n}^{\circ}$ 491/2001, os profissionais de letras deveriam "ter domínio do uso da língua ou das línguas que sejam objetos de seus estudos, em termos de sua estrutura, funcionamento e manifestações culturais". E espera-se deles múltiplas competências e habilidades para atuarem como "professores pesquisadores, críticos literários, revisores de textos, roteiristas, secretários, assessores culturais, entre outras atividades" (Brasil, 2001, p. 30). A articulação entre as habilidades e competências no curso de letras pressupõe, então, o desenvolvimento de atividades de caráter prático durante o curso. Portanto, havia uma expectativa de que ocorressem mudanças significativas na organização curricular e, consequentemente, na formação de uma nova geração de docentes.

Todavia, é possível afirmar que dificilmente o professor em formação na área de literatura teria condições de desenvolver habilidades que o fizessem cumprir satisfatoriamente seu papel de formador de leitores de literatura e de outros produtos culturais de modo crítico. Oliveira (2007), por exemplo, observou, pelo menos no que se refere aos programas de disciplinas investigados em sua pesquisa de doutorado, que em apenas uma das unidades universitárias o programa contemplava a articulação entre a disciplina de literatura brasileira e a área de metodologia de ensino, voltada para o estágio supervisionado. Isto indica que, embora a legislação vigente tenha acenado mudanças, nem todas foram concretizadas no espaço do cotidiano acadêmico.

\footnotetext{
${ }^{4}$ Resolução no 9 , de 10 de outubro de 1969, que estabeleceu a obrigatoriedade de Psicologia da Educação, Didática, Estrutura e Funcionamento de Ensino de $2^{\circ}$ Grau.
} 
É importante observar que, recentemente, a propósito da formação inicial em nível superior (cursos de licenciatura, cursos de formação pedagógica para graduados e cursos de segunda licenciatura) e da formação continuada, as diretrizes foram reformuladas a partir da Resolução CNE/CP no 2, de 1 de maio de 2015 (Brasil, 2015). Tal alteração novamente demandará aos cursos de licenciatura a reformulação de seus currículos visando implementar as alterações propostas, particularmente no que se refere ao mínimo de quatro anos de formação, com 3.200 horas (sendo 2.200 horas de conteúdo formativo; 400 horas de estágio; 400 horas de prática como componente curricular; 200 horas de atividades teórico-práticas de aprofundamento em áreas específicas de interesse dos estudantes ${ }^{5}$ ), entre outras especificidades.

De qualquer modo, reiterando as reflexões aqui apontadas, Cosson (2013) engrossa a discussão atual ao afirmar que esse estado de coisas ligado à abordagem do texto literário em sala de aula e à formação do professor - está, de fato, intimamente ligado à formação inadequada dos licenciados em letras e pedagogia. Por um lado, isso se deve ao fato de o curso de pedagogia, em seus anos de formação, focar quase que inteiramente as teorias educacionais e o processo de alfabetização, sem oferecer disciplina específica na área de literatura. ${ }^{6}$ Por outro, no caso do curso de letras, deve-se ao fato de os alunos não serem preparados para atuarem como professores de literatura, pois, ainda que possuam no programa curricular as disciplinas de literatura brasileira e portuguesa, bem como prática de ensino ou estágio supervisionado, o ensino recai (quase sempre) sobre a história da literatura ou sobre a língua portuguesa, respectivamente. ${ }^{7}$ Cabe enfatizar que se compreende o papel do professor universitário como mediador entre o texto literário e o público leitor, que, neste caso, é o professor em formação. Desse modo, sua própria formação deveria ter lhe dado condições de

\footnotetext{
${ }^{5}$ Entre elas: seminários, atividades práticas articuladas entre os sistemas de ensino e instituições educativas, mobilidade estudantil, atividades de comunicação e expressão.

${ }^{6}$ Exemplo disso é o curso de pedagogia da Universidade Estadual do Norte do Paraná, campus de Cornélio Procópio, que excluiu da matriz curricular a disciplina de literatura infantil, que atualmente passa por reformulação.

${ }^{7}$ No caso da Universidade Estadual do Norte do Paraná, campus de Cornélio Procópio, tem-se procurado alterar esse estado de coisas. Na matriz curricular vigente desde 2012, foram inseridas no curso de letras a disciplina de formação do professor em literaturas de língua portuguesa bem como em literatura infantil e juvenil, esta última em vigência desde 2006.
} 
desenvolver práticas de leitura crítica, capazes de ampliar seus horizontes e de fazê-lo atribuir sentidos aos produtos culturais que o circundam, de modo que ele possa "oferecer a [seu aluno] textos mais complexos do que aqueles com que ele se depara habitualmente, mostrar-lhe como os textos se inserem numa história e como produzem sentidos e valores" (Perrone-Moisés, 2002).

O professor universitário, tendo função formativa, como a própria universidade a tem, vê-se sempre diante de um dilema: o que se espera dele? De modo amplo, a resposta apontaria para um profissional com conhecimento específico em sua área de atuação, mas, ao mesmo tempo, com formação polivalente, que permita a ele ser flexível para se adaptar a situações diversas, atuando não só no ensino como também na pesquisa. Tudo isso aliado a um compromisso ético e social. Portanto, os conteúdos que o docente de letras seleciona para sua atuação na formação de outros professores estão ligados a esta dimensão formadora da prática pedagógica. As escolhas dos conteúdos, abordagens e metodologias adotadas revelam as influências que ele próprio recebeu e que estarão presentes na formação de seu aluno, por meio das atitudes, valores e visão de mundo expostos nas práticas cotidianas em sala de aula. Aqui, interessa a percepção que este professor em formação tem sobre conteúdo da área literária, como resultado dos processos de ensino-aprendizagem elaborados pelo docente na graduação.

Essas habilidades apontam para a necessidade, inclusive, de que estes graduandos sejam capazes de desempenhar o papel de mediadores no processo de desenvolvimento desses conteúdos, formando outros leitores e produtores textuais de modo crítico. Particularmente, destaca-se a educação literária, entendendo-a como um ato que potencializa a subjetividade do leitor em seu processo de formação e, por isso mesmo, favorece a compreensão das produções culturais e seus desdobramentos na constituição de identidades. Fica também a certeza de que, ao se falar sobre formação do professor de literatura, inúmeros fatores devem ser levados em conta, entre eles, principalmente, o de que a formação do leitor-professor também envolve práticas familiares e de seu contexto social, além daquelas que ele irá vivenciar na universidade. Isto significa compreender que ele é também um leitor comum, que irá se transformar num leitor institucional. 
Também é importante observar que, ao conceber a leitura como prática social, o docente passa a desempenhar seu papel de mediador no processo de formação do leitor, devendo ser um professor leitor. O papel da escola em todos os níveis é o de formar o cidadão e, para que isso ocorra, é preciso reformular constantemente a relação entre professor e aluno. Nesse sentido, a leitura, sobretudo aquela vinculada à literária, pode propiciar ao indivíduo a compreensão de seu papel na sociedade, daí a importância de desenvolver metodologias e estratégias interdisciplinares nas práticas de leitura propostas.

Então, para além da reflexão sobre a necessidade de readequações curriculares na formação do futuro professor de literatura, entram em cena também outras possibilidades de inserção do licenciando em atividades que possam promover a educação literária necessária para a abordagem do texto literário em sala de aula. Por isso, a importância das formações continuadas e de novas (alternativas) práticas metodológicas, pois está no fazer docente uma das possíveis soluções para a formação de leitores (literários).

Sob este aspecto, desde a sua criação, em 2007, o Programa Institucional de Bolsas de Iniciação à Docência (PIBID), mantido pela Coordenação de Aperfeiçoamento de Pessoal de Nível Superior (Capes), tem por objetivo provocar mudanças qualitativas no âmbito da formação de professores com impacto na educação básica em todas as regiões do Brasil. Ao longo deste período, o programa tem buscado a revitalização das licenciaturas, seja pelo compartilhamento de práticas formativas entre as diversas áreas de conhecimento; pela ampliação dos espaços de discussão sobre as práticas docentes; pela interlocução das instituições de ensino superior (IES) com as escolas e com a comunidade; pela vivência dos licenciandos com as comunidades escolares sob a supervisão de professores que integram o programa, os quais não somente são levados a ressignificar suas práticas educativas, mas também a atuar como coformadores; e, sobretudo, pelo interesse na melhoria da qualidade do ensino com práticas docentes diversificadas e interdisciplinares. Desse modo, os desafios postos pelo cotidiano das escolas tornam-se objetos de investigação para a pesquisa e para a construção de alternativas de intervenção que, por sua vez, desdobram-se em experiências formativas, as quais ampliam, intensificam e reforçam o diálogo das escolas com as IES.

Igualmente, no que se refere às políticas públicas para a promoção tanto da formação do mediador de leitura quanto de difusão 
do livro, outro programa significativo é o Programa Nacional Biblioteca da Escola (PNBE), “desenvolvido desde 1997, que tem o objetivo de promover $\mathrm{o}$ acesso à cultura e o incentivo à leitura nos alunos $\mathrm{e}$ professores por meio da distribuição de acervos de obras de literatura, de pesquisa e de referência" (Brasil, s.d.). ${ }^{8}$

Ambos os programas, embora com escopos diferenciados, convergem na busca por uma educação de qualidade, sobretudo quando se discute educação literária. $O$ primeiro interessa aqui por tratar das potencialidades para a formação do professor de literatura, uma vez que o licenciando se direciona para uma articulação efetiva entre teoria e prática com o texto literário em ambientes escolares, vivenciando-as. $\mathrm{O}$ segundo, por possibilitar a reflexão sobre a mediação e o estímulo da leitura do texto, buscando estratégias para o efetivo acesso ao acervo distribuído às escolas. Benedito Antunes, em $O$ ensino da literatura hoje (2015), ao refletir sobre a formação do professor mediador e registrar a existência de programas que distribuem livros nas escolas, resume bem a problemática do mediador de leitura ao observar:

Mas quem vai mediar a leitura desses livros? Isto é, quem vai estimular e ensinar os alunos a aproveitar esse material? É, em geral, um professor despreparado, que precisaria, ele próprio, aprender a ler com gosto e competência, pois ele não pôde dispor dessa formação. É claro que um livro na mão do jovem, mesmo que mal aproveitado, é sempre melhor do que nada, mas os altos investimentos pedem mais do que isso; pedem uma estrutura capaz de tornar essas iniciativas mais eficientes para a formação do verdadeiro leitor, aquele que lê, compreende e age em função da leitura (Antunes, 2015, p. 9).

Diante das questões apresentadas, registra-se a seguir certa experiência que buscou integrar as discussões sobre a formação inicial do professor de literatura, futuro mediador de leitura, e os dois programas referidos, na tentativa de, como afirma Antunes (2015, p. 12), defender o papel deste professor/mediador no esquema da comunicação literária, que é o de "iluminar a obra no detalhe de sua construção textual, participando discretamente da busca do sentido empreendida fundamentalmente pelos alunos".

\footnotetext{
${ }^{8}$ Para mais informações sobre a aplicabilidade do PNBE, ver Paiva (2012).
} 


\section{Dos programas à prática}

A Universidade Estadual do Norte do Paraná (Uenp) aderiu ao Programa Institucional de Bolsas de Iniciação à Docência (Pibid/Capes) em 2012, apresentando um projeto institucional composto por dez subprojetos abrangendo as áreas de matemática, letras português/inglês, ciências biológicas, filosofia, pedagogia e história.

O programa possui como um de seus objetivos valorizar a integração entre escolas públicas da educação básica e cursos de licenciatura. Tal proposição parte do entendimento de que, ao se estreitarem os vínculos entre universidade e escola, os alunos dos cursos de licenciatura terão a possibilidade de melhor fundamentar sua prática docente e, em decorrência disso, alcançar uma formação mais consistente. Além disso, a escola, com o professor supervisor como elo entre a instituição de ensino superior e a rede de educação básica, bem como os alunos envolvidos no projeto, também é beneficiada com a parceria, que pode trazer resultados positivos nas práticas cotidianas desenvolvidas nas diferentes áreas do saber.

Interessado, pois, nessa articulação entre a universidade e a rede básica, o Colegiado do curso de Letras: Português-Inglês, do Centro de Letras, Comunicação e Artes (CLCA), do campus Cornélio Procópio, integrou-se ao Projeto Institucional da Uenp por meio do subprojeto "Formação de Leitores: Práticas de Letramento e Produção Textual", desenvolvendo intervenção no contexto do Programa Salas de Apoio da Secretaria de Estado de Educação do Paraná, que tem o objetivo de atender às dificuldades de aprendizagem de crianças que frequentam as séries finais do ensino fundamental, alunos da $5^{\mathrm{a}}$ série $/ 6^{\circ}$ ano e $8^{\mathrm{a}}$ série $/ 9^{\circ}$ ano, em duas escolas públicas do município de Cornélio Procópio: a Escola Estadual André Seugling e a Escola Estadual Castro Alves.

Encerrado em dezembro de 2013, o subprojeto teve como aporte de material didático os livros remetidos pelo PNBE, integrando recursos recebidos pela escola com práticas mais producentes em sala de aula. Deste acervo, foram selecionadas quatro obras literárias para a elaboração das sequências didáticas implementadas na intervenção realizada junto às escolas: No meio da noite escura tinha um pé de maravilha, de Ricardo Azevedo (2008); O barbeiro e o judeu da prestação contra o sargento da motocicleta, de Joel Rufino dos Santos (2007); Deu no jornal, de Moacyr Scliar (2008), e Vendem-se unicórnios, de Índigo (2009). 
A equipe vinculada ao subprojeto era composta por 22 bolsistas de iniciação à docência, divididos em quatro subgrupos e supervisionados por três professoras da rede, a partir das orientações de um coordenador de área e três professores colaboradores da universidade. No período de agosto de 2012 a julho de 2013, foram executadas atividades sistematizadas de leitura literária, articulando produção escrita e multiletramento nas referidas salas de apoio.

A partir de 2014, o subprojeto PIBID do curso de Letras da área de língua portuguesa desdobrou-se em dois eixos. O Eixo 1 é voltado para o letramento literário, a partir dos pressupostos metodológicos de Rildo Cosson (2007), com a elaboração de sequências básicas e expandidas e o desenvolvimento de atividades sistematizadas de leitura literária. Com base nos grandes eixos sobre os quais se pauta o trabalho, articula o ensino da língua portuguesa - leitura (literatura e demais esferas sociais), oralidade, escrita e análise linguística - conforme as Diretrizes Curriculares da Rede Pública de Educação Básica do Estado do Paraná, segundo a qual:

é tarefa da escola possibilitar que seus alunos participem de diferentes práticas sociais que utilizem a leitura, a escrita e a oralidade, com a finalidade de inseri-los nas diversas esferas de interação. Se a escola desconsiderar esse papel, o sujeito ficará à margem dos novos letramentos, não conseguindo se constituir no âmbito de uma sociedade letrada (Paraná, 2008, p. 48).

Intitulado "Letramentos na Escola: Práticas de Leitura e Produção Textual", esta vertente do projeto previu, ainda, como aporte de material didático, adotar obras literárias remetidas às bibliotecas escolares pelo PNBE/MEC.

Já o Eixo 2 tem por objetivo levar os alunos a se apropriarem de alguns gêneros textuais que se encontram inseridos em diversas práticas sociais, tanto no âmbito da leitura como no da produção escrita. Para tanto, fundamenta-se nos estudos desenvolvidos pelo Grupo de Genebra, conhecidos como interacionismo sociodiscursivo (ISD), sobretudo, em sua vertente didática. Esse subprojeto possui dois coordenadores de área, professores vinculados à Uenp, quatro professores supervisores oriundos de escolas públicas de Cornélio Procópio e 21 bolsistas de iniciação à docência. ${ }^{9}$

\footnotetext{
${ }^{9}$ O Eixo 1 é composto por 11 alunos bolsistas e 2 professoras supervisoras, além da coordenadora de área, profa. dra. Ana Paula F. Nobile Brandileone, e da colaboradora, profa. dra. Vanderléia da Silva Oliveira.
} 
Em 2014 foram elaboradas duas sequências didáticas - uma voltada para o $9^{\circ}$ ano do ensino fundamental e outra para o $2^{\circ}$ ano do ensino médio -, cujas intervenções ocorreram em duas escolas públicas de Cornélio Procópio: Escola Estadual Monteiro Lobato e Escola Estadual Castro Alves. Do acervo do PNBE foram selecionadas as obras Terra Papagalli, de José Roberto Torero e Marcus Aurelius Pimenta (2000), e Letras finais, de Luís Dill (2005). Em 2015, o material didático organizado estava em processo de implementação, com previsão de término em dezembro. Nesse mesmo ano, houve substituição da escola parceira e, ${ }^{10}$ consequentemente, da professora supervisora, bem como da turma assistida ( $1^{\circ}$ ano do ensino médio). Do acervo do PNBE, foram selecionados os títulos Dois irmãos, de Milton Hatoum (2005), e A filha do escritor, de Gustavo Bernardo (2008). Vale destacar que, a fim de garantir a leitura integral dos livros selecionados, a direção das escolas adquiriu um exemplar para cada aluno.

É importante registrar que ambos os subprojetos tiveram origem a partir de reflexões sobre alguns índices oficiais, como o índice de desenvolvimento da educação básica (IDEB), e outras aferições, como o Programa Internacional de Avaliação de Alunos (em inglês, Programme for International Student Assessmen - Pisa), que indicavam a necessidade de se investir em estratégias de ensino e aprendizagem na área de língua portuguesa. Em 2012, quando o Pibid foi institucionalizado na Uenp, o Brasil ocupava o $58^{\circ}$ lugar entre os 65 países que participaram da avaliação. ${ }^{11}$

É notório, ainda, o fato de que o percurso histórico do ensino da língua portuguesa na educação básica e o confronto com a situação de "analfabetismo funcional", verificado por meio de resultados de avaliações e pesquisas de diversos matizes, trazem uma inquietante indagação ao professor que enfrenta uma realidade social contraposta a práticas de letramento em ampla escala, ainda que espaços como o do trabalho e dos negócios exijam cada vez mais um domínio linguístico maior que a simples alfabetização. Assim sendo, em relação à formação de leitores, observa-se que o contexto da educação básica aponta para a relevância em se discutir estratégias que possibilitem aos docentes

\footnotetext{
${ }^{10}$ Substituição da Escola Estadual Castro Alves pela Escola Estadual Zulmira Marchesi.

${ }^{11}$ No quesito leitura, o Brasil ocupa a $55^{\circ}$ lugar; e em matemática e em ciências, $58^{\circ}$ e $59^{\circ}$ lugares, respectivamente.
} 
identificar os maiores entraves no processo de ensino de leitura e escrita em seus diferentes gêneros no espaço escolar. Essa discussão, inclusive, encaminha-se para o fomento de políticas públicas de incentivo à promoção da leitura, numa perspectiva de letramento, como o PNBE, no âmbito das ações estabelecidas pelo Plano Nacional do Livro e Leitura (PNLL) de 2010. Por meio dele, as escolas públicas têm recebido, desde 1997, acervos de textos literários. Entretanto, percebe-se que, frequentemente, estes livros não são utilizados como leitura em sala de aula, seja pelo desconhecimento do teor dessas obras, seja por obstáculos metodológicos (Paiva, 2012).

Considerou-se também a prerrogativa de uso dos diversos gêneros textuais como objeto de ensino da língua portuguesa, expressa nas Diretrizes Curriculares de Língua Portuguesa para a Educação Básica do Paraná (2008), que afirmam ser papel do professor de língua portuguesa ofertar aos alunos a experiência de leitura de diferentes gêneros de textos, em especial os gêneros da esfera literária, com a finalidade de desenvolver capacidades leitoras e de escrita relevantes para a vida em sociedade. De acordo com o referido documento "o ensino aprendizagem de língua portuguesa visa aprimorar os conhecimentos linguísticos e discursivos dos alunos, para que eles possam compreender os discursos que os cercam e terem condições de interagir com esses discursos" (Paraná, 2008, p. 58). Desse modo, a escola se apresenta como o lócus privilegiado para o letramento do aluno.

Em decorrência disso, os subprojetos voltaram-se para a realização de atividades que envolvessem leitura e escrita, a partir do trabalho com gêneros literários, compreendendo ser relevante a integração de atividades com foco em letramento literário e produção textual, práticas que se complementam na relação do sujeito com o uso da linguagem.

Direcionando, portanto, os trabalhos sob a perspectiva do letramento, entende-se que não há o letramento, mas letramentos, os quais podem ser tomados sob vários pontos de vista: letramentos múltiplos e multissemióticos (Rojo, 2009), letramento crítico (Oliveira, 2009), letramento digital (Marcuschi; Xavier, 2005), letramento literário (Cosson, 2007) etc. No entanto, para a instrumentalização pedagógica dos projetos, optou-se por nortear os trabalhos a partir do letramento literário, considerando-se que a "prática da literatura, seja pela leitura, seja pela escrita, consiste exatamente em uma exploração das 
potencialidades da linguagem, da palavra e da escrita, que não tem paralelo com outra atividade humana" (Cosson, 2007, p. 16).

Com forte caráter de intervenção, os subprojetos aqui apresentados (2012-2013 e 2014-2018) foram realizados considerando as seguintes etapas: estudos de fundamentação teórico-metodológica; levantamento diagnóstico de dados do contexto educacional e do acervo bibliográfico PNBE; elaboração de estratégias de intervenção pautadas na proposta de letramento literário; execução das estratégias sob orientação dos supervisores, colaborador e coordenador na organização de material didático e corpus de pesquisa; além de elaboração de artigos acadêmicos para divulgação em eventos na área de letras.

Sem intenção de privilegiar uma etapa em detrimento das outras, uma vez que todas compõem as atividades dos subprojetos aqui apresentados e todas concorrem para o êxito ou não da proposta, enfatizamos aqui os encontros semanais de estudo para a discussão de textos teóricos sobre a especificidade do discurso literário ${ }^{12}$ e a análise de textos literários. O objetivo desses encontros era colocar a literatura, por ela mesma, em lugar de destaque. Para tanto, procurou-se despertar nos licenciados e nos professores supervisores a percepção de que a leitura do texto literário se caracteriza pela necessidade de conhecimento dos códigos que regem a escrita literária (Hansen, 2005), ou seja, que a leitura literária tem como condição básica o conhecimento das normativas que regem o "decoro" particular das composições literárias (Aguiar, 2000). Para Vincent Jouve (2012, p. 90-91), "uma das características fundamentais do texto literário (como de toda obra de arte) passa essencialmente pela forma", já que "a forma não pode ser isolada do conteúdo: ela faz parte do sentido". Para o estudioso, portanto, "entender uma obra de arte é, então, examinar as complexas relações entre o que é mostrado e o modo como se mostra" (Jouve, 2012, p. 91). Também para Bordini e Aguiar, a literatura, mais que qualquer outro gênero, favorece a descoberta de sentidos pela sua capacidade de reinscrever e/ou reinventar o mundo pela força da palavra:

A atividade do leitor de literatura se exprime pela reconstrução, a partir da linguagem, de todo o universo simbólico que as palavras

\footnotetext{
${ }^{12}$ Entre os textos lidos e discutidos, destacam-se: "A literatura e a formação do homem" e "Direito à literatura", de Antonio Candido; "Sobre algumas funções da literatura", de Umberto Eco (2003); "Modelos de letramento literário e ensino da literatura: problemas e perspectivas", de Miriam Zaponne (2008); e Por que estudar literatura?, de Vincent Jouve (2012).
} 
encerram e pela concretização desse universo com base nas vivências pessoais do sujeito. A literatura, desse modo, se torna uma reserva de vida paralela, onde o leitor encontra o que não pode ou não sabe experimentar na realidade (Bordini e Aguiar, 1983, p. 15).

Para além "do modo particular com que ela [a literatura] significa" (Jouve, 2012, p. 90), as discussões sobre o especificamente literário recaem também sobre o papel substantivo do texto literário na formação do leitor que, segundo Antonio Candido (1972), está vinculado a seu caráter emancipador e humanizador, atuando sobre o sujeito segundo diferentes funções: psicológica, formadora e de conhecimento de mundo. Não por outro motivo é que a literatura atua em favor da emancipação do indivíduo, agindo para a formação de sujeitos autônomos e capazes de compreender o mundo à sua volta. Entendendo a literatura como "algo que exprime o homem e depois atua na própria formação do homem" (Candido, 1972, p. 804), Candido defende a função formadora e, por isso, transformadora da literatura, seja porque "enriquece a nossa percepção e a nossa visão de mundo" (Candido, 1995, p. 248), seja por satisfazer uma das necessidades mais básicas do ser humano: a fantasia. Também para Vincent Jouve, a literatura exprime, como nenhum outro gênero, as dimensões do humano: "A leitura das 'grandes' obras literárias geralmente nos permite apreender um pouco mais sobre nós mesmos" (Jouve, 2012, p. 88-89).

Conhecer a maquinaria e o papel do texto literário, diferentemente do que muitos pensam, é mais do que fruição; é prática que requer o compromisso de conhecimento que todo saber exige:

É justamente por ir além da simples leitura que o letramento literário é fundamental no processo educativo. Na escola, a leitura literária tem a função de nos ajudar a ler melhor, não apenas porque possibilita a criação do hábito de leitura ou porque seja prazerosa, mas, sim, e sobretudo, porque nos fornece, como nenhum outro tipo de leitura faz, os instrumentos necessários para conhecer e articular com proficiência o mundo feito linguagem (Cosson, 2007, p. 30).

Desse modo, a leitura literária é uma prática que não se realiza naturalmente, sem esforço, mas solicita uma aprendizagem formal, sob pena de as leituras produzirem interpretações impertinentes ou inapropriadas para os textos. É o que alerta Vincent Jouve em A leitura: "Se, como mostramos, não se pode reduzir a obra a uma única interpretação, existem, entretanto, critérios de validação [...] a recepção é, em grande parte, programada pelo texto. Dessa forma, o leitor não 
pode fazer qualquer coisa [...]. Nem todas as leituras, portanto, são legítimas" (Jouve, 2002, p. 25-27).

Se, conforme estabelecem as Orientações Curriculares para o Ensino Médio, "faz-se necessário e urgente o letramento literário", isto é, "'letrar' literariamente o aluno, fazendo-o apropriar-se daquilo a que tem direito" (Brasil, 2006, p. 54-55), a literatura deve ser encarada como um saber necessário e não reduzido a apêndice da disciplina de língua portuguesa, quer pela sobreposição à simples leitura no ensino fundamental, quer pela redução da literatura à história literária no ensino médio. Para tanto, faz-se premente que o debate em torno do letramento literário passe antes pela prática docente, ou seja, pela formação do professor que, atuando como mediador no processo de construção do letramento literário, possa conceder à literatura a autonomia e a especificidade que lhe são devidas.

Sob essa perspectiva é que o Pibid se institui como instância de qualificação na formação docente dos bolsistas envolvidos - formação inicial para os bolsistas de iniciação à docência e formação continuada para os bolsistas supervisores. Por um lado, favorece aos licenciados em formação a possibilidade de refletir sobre o agir docente e sobre o processo de ensino-aprendizagem da língua - sobretudo pelo viés do letramento literário -, bem como de articular teoria e prática. Por outro, propicia às professoras supervisoras conhecer e vivenciar novos procedimentos didáticos relacionados ao ensino da produção textual e do letramento literário.

Considerando esse último aspecto é que a proposta de letramento literário de Cosson (2007) assume relevante estratégia metodológica no direcionamento, fortalecimento e ampliação da educação literária oferecida aos alunos, a fim de torná-los leitores proficientes e perenes, dentro e fora do contexto escolar. Lembrando que é pela sistematização dos procedimentos didáticos que a finalidade para o ato de aprender se concretiza:

É fundamental que se coloque como centro das práticas literárias na escola a leitura efetiva dos textos, e não as informações das disciplinas que ajudam a constituir essas leituras, tais como a crítica, a teoria ou a história literária. Essa leitura também não pode ser feita de forma assistemática e em nome de um prazer absoluto de ler. Ao contrário, é fundamental que seja organizada segundo os objetivos da formação do aluno, compreendendo que a literatura tem um papel a cumprir no âmbito escolar (Cosson, 2007, p. 23). 
Também Bordini e Aguiar (1983) chamam atenção para a importância de o professor possuir metas bastante definidas para orientar as expectativas educativas:

Nesse sentido todas as etapas do processo ensino aprendizagem estariam voltadas para os fins últimos da educação. Esse princípio norteador das experiências educativas seria a espinha dorsal de um método, o qual se resume em um conjunto de atividades com um nexo sistemático entre si (1983, p. 41).

Se, por um lado, o Pibid, considerando as experiências pedagógicas aqui relatadas, favorece a "escolarização"13 da literatura, centrando suas ações no objetivo de recuperar a leitura literária no espaço escolar e, assim, "garantir a função essencial de construir e reconstruir a palavra que nos humaniza" (Cosson, 2007, p. 27), por outro lado, o uso do acervo do PNBE concorre para efetivar uma política pública já consolidada, mas que carece de iniciativas que promovam a leitura dessas obras. A fim, portanto, de viabilizar o reconhecimento do material disponibilizado e suas possibilidades educativas no cotidiano escolar, é que os subprojetos aqui apresentados propõem-se a colocar para "fora da caixa" os livros literários distribuídos sistematicamente para as bibliotecas de escolas públicas de todo país, adotando uma prática de leitura literária a partir dos acervos do PNBE. É, pois, conjugando duas políticas públicas, uma de formação docente que, em última instância, forma mediadores de leitura e, outra, de formação de leitores, que se pretende assegurar à literatura um lugar de destaque nas áreas do conhecimento.

Entretanto, quando se coloca a literatura e seu ensino em pauta, sob o pressuposto de defender seu espaço nas práticas escolares e assegurar a sua importância para a formação integral do cidadão, é preciso que se compreenda que o universo escolar, em toda a sua gestão - diretor, professores coordenadores, bibliotecários, orientadores pedagógicos e funcionários -, assume responsabilidades na promoção do letramento literário.

\section{Referências}

${ }^{13}$ Entende-se a escolarização como sendo a apropriação do texto literário no espaço escolar, de modo a escolarizá-la e didatizá-la. 
AGUIAR, Flávio Wolf de (2000). As questões da crítica literária. In: MARTINS, Maria Helena (Org.). Outras leituras: literatura, televisão, jornalismo de arte e cultura, linguagens interagentes. São Paulo: Itaú Cultural.

ANTUNES, Benedito (2015). O ensino da literatura hoje. Revista FronteiraZ, n. 14, jul.

BORDINI, Maria da Glória; AGUIAR, Vera Teixeira (1988). Literatura: a formação do leitor - Alternativas metodológicas. Porto Alegre: Mercado Aberto.

BRASIL. Conselho Nacional de Educação (2001). Parecer MEC/CNE/CES $n^{\circ}$ 491/2001, de 4 de julho de 2001. Diretrizes curriculares nacionais dos cursos de filosofia, história, geografia, serviço social, comunicação social, ciências sociais, letras, biblioteconomia, arquivologia e museologia. Diário Oficial da União, Brasília, seção 1e, p. 50, 9 jul.

BRASIL. Conselho Nacional de Educação (2002). Resolução MEC/CNE/CP n ${ }^{\circ}$ 02/2002, de 19 de fevereiro de 2002. Institui a duração e a carga horária dos cursos de licenciatura, de graduação plena, de formação de professores da Educação Básica em nível superior. Diário Oficial da União, Brasília, seção 1, p. 9, 4 mar.

BRASIL. Conselho Nacional de Educação (2015). Resolução MEC/CNE/CP n ${ }^{\circ}$ 02/2015, de $1^{\circ}$ de julho de 2015. Define as Diretrizes Curriculares Nacionais para a formação inicial em nível superior (cursos de licenciatura, cursos de formação pedagógica para graduados e cursos de segunda licenciatura) e para a formação continuada. Diário Oficial da União, Brasília, seção 1, p. 8-12, 2 jul.

BRASIL. Ministério da Educação (s.d.). Programa Nacional Biblioteca da Escola. Online. Brasília. Disponível em: https:/ / goo.gl/XxAlNH. Acesso em: 11 nov. 2015.

BRASIL. Ministério da Educação. Secretaria de Educação Média e Tecnológica (2006). Orientações curriculares para o ensino médio. Ciências da Natureza, Matemática e suas Tecnologias. Brasília: MEC/SEB.

BRASIL. Senado Federal. (1996). Lei no 9.394, de 20 de dezembro de 1996. [Lei de Diretrizes e Bases da Educação Nacional]. Estabelece as diretrizes e bases da educação nacional. Diário Oficial [da] República Federativa do Brasil, Brasília, 23 dez.

CANDIDO, Antonio (1972). A literatura e a formação do homem. Ciência $e$ Cultura. São Paulo, v. 4, n. 9, p. 803-809, set.

CANDIDO, Antonio (1995). O direito à literatura. In: CANDIDO, Antonio. Vários Escritos. 3. ed. São Paulo: Duas Cidades.

COSSON. Rildo (2007). Letramento literário: teoria e prática. São Paulo: Contexto.

COSSON, Rildo (2013). A formação do professor de literatura: uma reflexão interessada. In: PINHEIRO, Alexandra Santos; RAMOS, Flávia Brocchetto (Org.) 
Literatura e formação continuada de professores: desafios da prática educativa. Campinas: Mercado de Letras.

ECO, Umberto (2003). Sobre algumas funções da literatura. In: ECO, Umberto. Sobre a literatura. Tradução de Eliana Aguiar. Rio de Janeiro: Record.

HANSEN, João Adolfo (2005). Reorientações no campo da leitura literária. In: ABREU, Márcia; SCHAPOCHNIK, Nelson. Cultura letrada no Brasil: objetos e práticas. Campinas: Mercado de Letras.

JOUVE, Vincent (2002). A leitura. São Paulo: Editora Unesp.

JOUVE, Vincent (2012). Por que estudar literatura? Tradução de Marcos Bagno e Marcos Marcionilo. São Paulo: Parábola.

MARCUSCHI, Luiz Antônio; XAVIER, Antônio Carlos (Org.) (2005). Hipertexto e gêneros digitais: novas formas de construção de sentidos. 2. ed. Rio de Janeiro: Lucerna.

OLIVEIRA, Maria do Socorro (2009). Gêneros textuais e letramento. In: SIMPÓSIO INTERNACIONAL DE ESTUDOS DE GÊNEROS TEXTUAIS (SIGET) - O Ensino em Foco, 5., 11-14 ago. 2009, Caxias do Sul. Anais... Caxias do Sul: UCS. (1 CD-ROM).

OLIVEIRA, Vanderléia da Silva (2007). História literária nos cursos de letras: cânones e tradições. 410f. Tese (Doutorado em Letras) - Universidade Estadual de Londrina, Londrina.

PAIVA, Aparecida (Org). (2012). Literatura fora da caixa: o PNBE - distribuição, circulação e leitura. São Paulo: Editora UNESP.

PARANÁ. Secretaria de Estado da Educação (2008). Diretrizes Curriculares de Língua Portuguesa para a Educação Básica. Curitiba.

PERRONE-MOISÉS, Leila (2002). A literatura como mediação. In: CONGRESSO INTERNACIONAL ABRALIC - Mediações, 8., 23-26 jul. 2002, Belo Horizonte. Anais... Belo Horizonte: UFMG. CD-ROM.

ROJO, Roxane (2009). Letramentos múltiplos, escola e inclusão social. São Paulo: Parábola.

ZAPONNE, Miriam (2008). Modelos de letramento literário e ensino da literatura: problemas e perspectivas. Revista Teoria e Prática da Educação, Maringá, v. 11, n. 1, p. 46-60, jan/abr.

ZILBERMAN, Regina (1991). A leitura e o ensino da literatura. 2. ed. São Paulo: Contexto. 
Recebido em fevereiro de 2016.

Aprovado em agosto de 2016.

\section{resumo/abstract/resumen}

\section{O lugar do PNBE e do PIBID na e para a formação de leitores}

Ana Paula Franco Nobile Brandileone

Vanderléia da Silva Oliveira

Nos últimos anos muito se tem discutido sobre a formação de leitores, sobretudo depois que começaram a ser difundidos os baixos índices de leitura dos estudantes no Brasil. Contribuições e estratégias de toda ordem - das mais teóricas às mais práticas - têm sido adotadas com o objetivo de superar esse estado de coisas. No incentivo à leitura e à formação de leitores ganha destaque o Programa Nacional Biblioteca na Escola (PNBE/MEC) que, desde 1997, tem atuado com o objetivo de democratizar o acesso a obras de literatura brasileira e estrangeira infantis e juvenis, além de fornecer materiais de pesquisa e de referência a professores e alunos das escolas públicas brasileiras. Já o Programa Institucional de Bolsas de Iniciação à Docência (PIBID/CAPES), criado em 2007, centra suas ações tanto na formação continuada de professores, os quais são levados a ressignificar suas práticas educativas, atuando como elo entre a rede de educação básica e instituição de ensino superior, quanto na formação inicial de licenciandos, uma vez que os alunos dos cursos de licenciatura tem a possibilidade de fundamentar melhor a sua prática docente e, em decorrência disso, alcançarem uma formação mais sólida. É objetivo deste artigo discutir a importância destas duas políticas públicas para a promoção da leitura literária e para a qual a mediação assume, cada vez mais, aspecto essencial na e para a formação de leitores.

Palavras-chave: formação de leitores, PNBE, PIBID, mediação.

\section{The role of PNBE and PIBID in and for readers' education}

Ana Paula Franco Nobile Brandileone

Vanderléia da Silva Oliveira

In recent years, there have been several discussions about the education of readers, mainly after the disclosure of the low reading scores of Brazilian students. Contributions and strategies of all kinds - from the most theoretical to the most practical - have been adopted in order to overcome this state of affairs. Amongst these initiatives, the National Program for School Libraries (PNBE / MEC) stands out. Since 1997 the program has worked to democratize students' access to Brazilian 
and foreign youth and children's literature and to provide teachers and students in Brazilian public schools with research and reference materials. Another program, the Institutional Program of Scholarship for the Introduction to Teaching (PIBID / CAPES), created in 2007, has focused its efforts in two directions: continuing education of teachers, which are encouraged to reshape their educational practices, acting as a link between elementary education networks and institutions of higher education. In addition, the PIBID/CAPES also impacts undergraduate education in that the students enrolled in degree courses have the opportunity to improve their teaching practices and, therefore, achieve a more solid pedagogical formation. The aim of this article is to discuss the importance of these two public policies to promote literary reading. In both cases, mediation has become an increasingly important aspect in and for the training of readers.

Keywords: Readers' education, PNBE, PIBID, mediation.

\section{El lugar del PNBE y del PIBID en la y para la formación de lectores}

\section{Ana Paula Franco Nobile Brandileone}

Vanderléia da Silva Oliveira

En los últimos años se ha discutido mucho acerca de la formación de lectores, sobre todo después que empezaron a ser difundidos los bajos índices de lectura de los estudiantes en Brasil. Contribuciones y estrategias de todo orden - desde las más teóricas hasta las más prácticas - han sido adoptadas con objetivo de superar ese estado de cosas. En el rubro de incentivo a la lectura y a la formación de lectores se destaca el Programa Nacional Biblioteca en la Escuela (PNBE/MEC) que, desde 1997, ha actuado con el objetivo de democratizar el acceso a las obras de literatura brasileña y extranjera infantiles y juveniles, además de proporcionar materiales de investigación y de referencia a los profesores y alumnos de las escuelas públicas brasileñas. Ya el Programa Institucional de Becas de Iniciación a la Docencia (PIBID/ CAPES), creado en 2007, centra sus acciones tanto en la formación continuada de profesores, los cuales son llevados a resignificar sus prácticas educativas, actuando como un eslabón entre la red de educación básica y la institución de enseñanza superior, cuanto en la formación inicial de los licenciados, una vez que los estudiantes de los cursos de licenciatura tienen la posibilidad de fundamentar mejor su práctica docente y, en consecuencia, lograr una formación más sólida. El objetivo de este artículo es discutir la importancia de estas dos políticas públicas para la promoción de la lectura literaria y para la cual la mediación asume, cada vez más, un aspecto esencial en la y para la formación de lectores.

Palabras clave: formación de lectores, PNBE, PIBID, mediación. 